\title{
TRANSMISSÃO DE CALOR: O QUE DIZEM AS PESQUISAS DOS ÚLTIMOS DEZ ANOS A RESPEITO?
}

\section{ARTIGO ORIGINAL}

PEREIRA, Marlúcia de Aquino ${ }^{1}$

MACÊDO, Haroldo Reis Alves de ${ }^{2}$

PEREIRA, Marlúcia de Aquino. MACÊDO, Haroldo Reis Alves de. Transmissão de calor: 0 que dizem as pesquisas dos últimos dez anos a respeito? Revista Científica Multidisciplinar Núcleo do Conhecimento. Ano 06, Ed. 01, Vol. 02, pp. 139160. Janeiro de 2021. ISSN: 2448-0959, Link de acesso: https://www.nucleodoconhecimento.com.br/educacao/transmissao-de-calor

\section{RESUMO}

Este trabalho trata-se de uma pesquisa bibliográfica que teve como objetivo geral analisar pesquisas desenvolvidas no Brasil sobre o ensino dos processos de transferência de calor para o Ensino Médio, e específicos pesquisar trabalhos que abordam o ensino dos processos de transmissão de calor no Ensino Médio, descrever o cenário dessas pesquisas e apresentar métodos de ensino e suas contribuições para esse conteúdo através de pesquisas já existentes. O estudo se deu a partir da seguinte problemática: Como os processos de transmissão de calor vêm sendo trabalhados em pesquisas no Ensino Médio? A pesquisa foi realizada na Biblioteca Brasileira de Teses e Dissertações (BDTD) e no portal de periódicos da capes. Foram encontrados 301 trabalhos que abordam os processos de transmissão de calor, porém apenas seis deles são voltados para o ensino desse conteúdo, entre eles tem-se cinco

\footnotetext{
${ }^{1}$ Pós Graduanda em Ensino de Ciências da Natureza-Universidade Federal do Piauí, UFPI.

2 Doutor em Ciência e Engenharia de Materiais- Universidade Federal do Rio Grande do Norte, UFRN.
} 
dissertações e um artigo. A análise dos trabalhos foi realizada de maio a junho de 2020. Nos trabalhos analisados percebeu-se a aplicação de algumas metodologias de ensino que tinham como objetivo a diversificação das atividades para a facilitação do aprendizado, dentre as atividades dispostas nos trabalhos estão: experimentos laboratoriais e de baixo custo, aulas teóricas, jogos, textos, slides, mapa conceitual e robótica com prevalência de atividades experimentais. No geral, percebeu-se o uso de práticas de ensino que fogem do tradicionalismo, mas ao mesmo tempo sem abandonar as práticas tradicionais que também são de fato importantes para a educação, e em todos eles foram apresentados melhorias na aprendizagem dos estudantes ao contextualizar o conteúdo com situações cotidianas e utilizar experimentos.

Palavras-chave: Ensino de Física, transmissões de calor, estratégias de ensino.

\section{INTRODUÇÃO}

Ao longo dos anos a sociedade se transforma, as necessidades de modo geral mudam, e na área da educação não é diferente, pois o ensino deve acompanhar essas transformações. O ensino tem passado por reformulações na busca por uma educação que atenda às muitas exigências de formação do mercado globalizado, com isso, busca-se promover um aprendizado que possa ser utilizado fora da escola, abordando situações da vida prática, e que permita aos indivíduos viverem e atuarem na sociedade moderna. (MACHADO, 2015).

A Física, consta nos documentos oficiais como componente curricular de Ciências da Natureza, e as dificuldades no ensino dessa disciplina comumente são associadas a falta de relação dos conceitos científicos estudados na escola com a realidade (fenômenos reais) e cotidianos dos estudantes e também na pouca habilidade dos discentes com os cálculos matemáticos. (SILVA, 2019).

Para que o ensino de Física, atinja as competências almejadas atualmente para o Ensino Médio são indispensáveis mudanças, mais precisamente nas práticas de ensino, tornam-se então necessários estudos, pesquisas e formação que possibilite 
contextualização, conforme orientações em alguns documentos como na Lei de diretrizes e base da educação nacional (LDB), Parâmetros Curriculares Nacionais (PCNs), e mais recentemente da Base nacional comum curricular (BNCC).

A Base Nacional Comum Curricular (BNCC) dispõe que "[...] a área de Ciências da Natureza e suas Tecnologias propõe que os estudantes possam construir e utilizar conhecimentos específicos da área para argumentar, propor soluções e enfrentar desafios locais e/ou globais, relativos às condições de vida e ao ambiente" (BRASIL, 2017, p. 470).

Dessa forma, as pesquisas em ensino de Física são essenciais, e assim, surgiu o interesse por essa pesquisa, por meio do seguinte questionamento: Como os processos de transmissão de calor vêm sendo trabalhados em pesquisas no Ensino Médio?

Esse trabalho teve como objetivo geral analisar pesquisas desenvolvidas no Brasil sobre o ensino dos processos de transferência de calor para o Ensino Médio utilizando como base a BDTD e o portal de periódicos da capes, e específicos: pesquisar trabalhos que abordam o ensino dos processos de transmissão de calor no Ensino Médio, descrever o cenário dessas pesquisas e apresentar métodos de ensino e suas contribuições para esse conteúdo através de pesquisas já existentes.

Os processos de transmissão de calor são trabalhados nas aulas de Física do $2^{\circ}$ ano do Ensino Médio. Optou-se por esse conteúdo devido ele ter muitas aplicações no cotidiano, e por comumente ser estudado prevalecendo estudo teórico e decorativo normalmente desvinculado de entendimento e aplicações cotidianas.

Esse trabalho apresenta o panorama das pesquisas realizada nessa temática no Brasil no período de 2010 a 2020, e contribui para nortear pesquisadores que se interessam pelo tema, mas principalmente é um material de apoio e inspiração para professores que buscam atualizar suas práticas de ensino e desejam diversificar as atividades. 


\section{ENSINO DE FÍSICA: COMO É E COMO DEVE SER}

De acordo com Nascimento (2010) considerando que a sociedade depende da ciência e da tecnologia, a educação cientifica é imprescindível para o povo, por ser uma ciência da natureza a Física precisa estar presente na vida dos indivíduos que pretendem ser ativos no meio social, assim como deve também receber a devida atenção do governo responsável, para o ensino e pesquisas. O autor afirma ainda que "conceitos de Física devem ser incorporados como ferramentas ou recursos aos quais os educandos possam recorrer para resolver situações ligadas ao seu dia a dia" (NASCIMENTO, 2010, p. 22).

A respeito do ensino das ciências da natureza no ensino médio a BNCC explica que:

No Ensino Médio, a área deve, portanto, se comprometer, assim como as demais, com a formação dos jovens para o enfrentamento dos desafios da contemporaneidade, na direção da educação integral e da formação cidadã. Os estudantes, com maior vivência e maturidade, têm condições para aprofundar o exercício do pensamento crítico, realizar novas leituras do mundo, com base em modelos abstratos, e tomar decisões responsáveis, éticas e consistentes na identificação e solução de situações-problema. (BRASIL, 2017, p.537).

Desse modo, é preciso educar para a Ciência de maneira que esta sirva para propósitos maiores dentro da sociedade, isso inclui promover uma educação científica que coloque os sujeitos em contato com situações reais, por exemplo com os possíveis prejuízos que surgem da exploração sem limites dos ambientes naturais e destruição do meio ambiente. (ARAUJO; CHESINI e ROCHA FILHO, 2014).

As aulas de Física comumente se limitam a reproduzir cálculos matemáticos, de forma abstrata, sem sentido conceitual e distante da realidade do estudante, para a autora isso contribui para que os estudantes vejam a Física como uma disciplina complicada e que é impossível aprendê-la (SILVA, 2019). "As aulas expositivas que apela exclusivamente para a memorização não são as únicas alternativas para ensinar Física, nem são as melhores" (NASCIMENTO, 2010, p. 16). 
"É importante dizer que o desafio do professor e da professora no ambiente escolar é estar sempre investigando diferentes estratégias de ensino e aprofundar alternativas que possam auxiliar sua prática, visando impulsionar o desenvolvimento das aprendizagens dos alunos" (SILVA, 2019, p.14). A autora acrescenta ainda que não há uma receita pronta para o professor obter êxito nas aulas, compete tornar as técnicas de ensino adaptáveis a sua realidade, e para isso professores precisam de boa formação, associando teoria e prática, para que possa interagir, fazer modificação nas práticas de ensino e atingir os objetivos de ensino.

Essa responsabilidade não é única e exclusiva dos professores, são muitos os fatores que interferem na educação, como também são muitos os responsáveis ligados ao processo de ensino e aprendizagem. Machado (2015) ressalta que o ensino de Física tem relação com habilidades como o Cálculo e a Linguagem, isso exigi em muitos momentos que o estudante tenha que calcular, ler, interpretar, analisar, e a dificuldade com alguma dessas habilidades possivelmente podem gerar, em alguns momentos, durante atividades, a não efetivação do que se espera. Às vezes é necessário que os estudantes tenham alguns pré-requisitos para que o aprendizado de novos temas se consolide.

Um Ensino de Física baseado em mediações como transmissão de conhecimentos descontextualizados; matematização sem justificativa; afirmações categóricas sobre os conhecimentos científicos; pouca consideração da realidade estudantil e escolar e pequena ou nenhuma participação dos alunos no processo mantém os significados já tradicionalmente difundidos para o Ensino de Física e pode não colaborar para a atribuição de sentidos novos pelos estudantes. (PEREIRA, 2020, p. 4).

Com a sociedade da informação surgem diferentes perspectivas no que se refere ao pensamento e as práticas, ação e comunicação, respeitando-se as diferentes formas de agir e pensar de acordo com a realidade de cada indivíduo. Numa sociedade moderna, os hábitos se transformam em maneiras de construir conhecimentos por diferentes instrumentos que podem ir de encontro com as necessidades de estudantes proporcionando uma construção de aprendizagem significativa. (HABERMANN e COELHO, 2019). 
Os conhecimentos elaborados por intermédio das relações entre a reflexão sobre práxis, a análise crítica da realidade escolar e as contribuições das pesquisas acadêmicas em Educação, em geral, e em Ensino, em particular, podem permitir ao professor e aos demais atores do contexto escolar atuarem com vistas a disponibilizar novos significados para o Ensino de Física, como, por exemplo: a percepção da Física como construção humana; a relevância dos conhecimentos físicos para a explicação de fenômenos da natureza; a importância do Ensino de Física para uma atuação cidadã crítica em sociedade (PEREIRA, 2020, p.4).

Ao estudar transferências de calor, por exemplo, é importante compreender conceitos científicos que são usados comumente no dia a dia de forma equivocada como calor, temperatura e sensação térmica, bem como o ensino pode ser direcionado para situações práticas e aplicáveis dos processos de condução, radiação e convecção, tal conhecimento é base para estudos seguintes como também para atitudes rotineiras da vida cotidiana, como uso adequado de materiais de acordo com sua condutividade térmica, melhor aproveitamento de utensílios e eletrodomésticos.

A compreensão da ocorrência de alguns fenômenos ambientais, e como o indivíduo pode estar contribuindo ou não para sua intensificação também é um fator a ser explorado, de modo que esses conhecimentos possam influenciar pequenas atitudes diárias de forma positiva na vida dos indivíduos.

As competências especificas de ciências da natureza citadas na BNCC são voltadas para uso do conhecimento no cotidiano, estão entre essas competências:

Analisar fenômenos naturais e processos tecnológicos, com base nas relações entre matéria e energia, para propor ações individuais e coletivas que aperfeiçoem processos produtivos, minimizem impactos socioambientais e melhorem as condições de vida em âmbito local, regional e/ou global. (BRASIL, 2017, p.539).

\section{TRANSFERÊNCIAS DE CALOR E SUAS APLICAÇÕES NO COTIDIANO}

Compreende-se calor como uma forma de energia que é transferida de um corpo para outro por causa da diferença de temperatura entre eles. A transferência de calor 
ocorre, espontaneamente, de um corpo com maior temperatura para outro corpo com menor temperatura. Esse processo cessa quando os corpos envolvidos nas trocas de energia térmica alcançam a mesma temperatura, atingindo assim o equilíbrio térmico (MARTINI et al., 2016). "A temperatura de um corpo é uma medida do grau de agitação de seus átomos ou moléculas" (BARRETO FILHO e XAVIER, 2016, p. 25).

Barreto Filho e Xavier (2016) acrescentam ainda que em outros termos temperatura é a grandeza Física que fornece a medida, de forma indireta, da energia cinética média (energia térmica) das partículas que compõe um sistema, tal medida pode ser obtida pelo uso de termômetros.

O calor pode ser transferido entre corpos por processos conhecidos como condução, convecção e irradiação, de modo que: "A condução térmica é um processo de propagação de calor que se realiza pela transmissão da agitação térmica de partículas de uma região com maior temperatura para partículas de uma região vizinha com menor temperatura" (MARTINI et al., 2016, p. 20).

Para que ocorra condução térmica é necessário que existam partículas que transportem a energia térmica, ou seja, deve existir um meio material por onde o calor possa se propagar, assim ela ocorre em sólidos, líquidos e gases. A grandeza física condutividade térmica diferencia os materiais em relação à condução de calor: bons condutores têm maior condutividade, maus condutores têm menor condutividade. Quanto maior a condutividade, mais fácil ocorre a condução. (MARTINI et al., 2016).

Barreto Filho \& Xavier (2016) explicam que esse processo necessita de meio material, o calor se propaga em razão da agitação térmica dos átomos que compõe o material, sem que haja transporte de matéria. A rapidez (taxa de transmissão) com a qual o calor é transferido por condução pode ser medida pela Lei de Fourier, matematicamente expressa por:

$$
\Phi=\frac{\Delta \mathrm{Q}}{\Delta \mathrm{t}} \quad \Rightarrow \quad \Phi=\mathrm{K} \frac{\mathrm{A}\left(\mathrm{T}_{2}-\mathrm{T}_{1}\right)}{\mathrm{L}}
$$


Onde, é o fluxo de calor, variação do tempo, quantidade de calor transferida, $\mathrm{K}$ coeficiente de condutividade, $\mathrm{L}$ comprimento e A seção transversal de área.

Os materiais possuem coeficiente de condutividade $\mathrm{K}$ característico, que representa quanto calor é conduzido por segundo, através de uma camada de $1 \mathrm{~m}$ de espessura por $1 \mathrm{~m}^{2}$ de área, numa diferença de temperatura de $1^{\circ} \mathrm{C}$ entre as extremidades da camada. A aplicação dos materiais depende da situação. (BARRETO FILHO e XAVIER, 2016).

Os conhecimentos sobre a condução térmica têm diversas aplicações cotidianas, tais como: Panelas de metal possuem cabo de materiais isolantes térmicos para evitar queimaduras. Bebidas resfriam mais rapidamente em latas do que em garrafas de vidro ou plástico porque metais são melhores condutores do que vidro e plástico. Os filamentos dos resistores de um forno elétrico se aquecem através da condução térmica. Pessoas têm naturalmente a tendência de se encolher ao sentir frio, pois isso faz diminuir a área de contato com o ambiente e quanto maior a superfície de contato, mais facilmente ocorre a condução. (SANT' ANNA et al., 2010).

O segundo processo citado é a convecção, esse processo é caracterizado pelo transporte de matéria entre as regiões de um sistema (corpo ou meio) e ocorre apenas em fluidos, que são os líquidos e gases, esse movimento de matéria ocorre devido à diferença de densidade existente nos fluidos. (MARTINI et al., 2016).

Quando aquecido o corpo tende a dilatar-se, quanto maior o volume, menor a densidade, ao ser resfriado o volume do corpo tende a diminuir, consequentemente a densidade aumenta. A densidade (d) de um corpo é fornecida pela razão entre massa (m) e volume (v), (MARTINI et al., 2016).

$$
\mathrm{d}=\frac{\mathrm{m}}{\mathrm{v}}
$$


Ao utilizar a chama do fogo para aquecer água em uma panela, ocorre um movimento de sobe e desce de massa líquida dentro da panela, devido a porção de líquido mais próxima da chama ser aquecida e dilatar-se, como resultado tem sua densidade diminuída, isso faz com que essa camada suba e as camadas mais frias (mais densas), desçam, esse processo continua enquanto tem chama, as correntes em circulação são denominadas de correntes de convecção (BARRETO FILHO e XAVIER, 2016).

Nos refrigeradores de uma porta, o congelador é colocado na parte superior, para facilitar a formação das correntes de ar no sentido descendente, o compartimento de carnes fica na parte superior, pois ela entra em decomposição facilmente, e os vegetais na parte de baixo por serem mais resistentes, as prateleiras vazadas, em algumas, facilitam a circulação do ar. (BARRETO FILHO e XAVIER, 2016)

As brisas marítimas e terrestres são correntes de convecção, no decorrer do dia a terra tem temperatura maior que a água, desse modo o ar acima da terra também está com a temperatura maior do que o ar acima do mar, portanto o ar terrestre (menos denso) tende a subir. E o ar que estava sobre o mar ocupa o lugar antes ocupado pelo o ar terrestre, então durante o dia a brisa que vem do mar para a terra e a noite ocorre o contrário. (MARTINI et al., 2016).

Por fim a transferência de calor através da radiação ou irradiação é o processo em que a energia é transportada por meio de ondas eletromagnéticas (radiação infravermelha), esse processo ocorre tanto no vácuo como em meios materiais, e não depende de meio material. (MARTINI et al., 2016).

Os corpos emitem radiações térmica independente da temperatura em que estão, e quanto maior for a temperatura, maior será a intensidade da radiação emitida. Quando a energia radiante incide em um corpo qualquer, ele absorve uma parte, outra parte é refletida e a outra pode ser transmitida através desse corpo. Ao receber radiação os corpos se aquecem proporcionalmente à sua capacidade de absorver energia, os corpos com boa capacidade de absorção, também são bons emissores. (BARRETO FILHO e XAVIER, 2016). 
De modo geral, corpos escuros possuem alta capacidade de absorção e baixa refletividade, e corpos claros e polidos possuem baixa capacidade de absorção e alta refletividade, por isso, roupas escuras aquecem mais que roupas claras. (BARRETO FILHO e XAVIER, 2016).

Existem vários tipos de radiações: radiação visível (luz), radiação ultravioleta, raios $x$, raios gama etc. A que aquece os objetos é denominada radiação infravermelha ou radiação térmica. A radiação infravermelha tem várias aplicações, desde terapêuticas até bélicas. Através de sensores e outros dispositivos, pode-se transformar a radiação térmica em luz visível, o que torna possível "ver" na escuridão. (GONÇALVES FILHO e TOSCANO, 2013, p.30).

Há aplicações desse processo, por exemplo, em estufas para cultivo, estas têm paredes de vidro e piso pintado com cor escura, assim a radiação solar atravessa o vidro e é absorvida pelo piso e pelas plantas, que se aquecem e emitem parte da energia radiante na forma de raios infravermelhos, que ficam presos na estufa, o funcionamento dos coletores de energia solar, com paredes de vidro e fundo escuro, é semelhante. A terra passa por um processo parecido com o da estufa, alguns gases absorvem a radiação infravermelha emitida pelos raios solares, consequentemente 0 planeta perde pouco calor para o espaço e é isso que mantém a temperatura estável. (BARRETO FILHO e XAVIER, 2016).

\section{METODOLOGIA}

A pesquisa é do tipo bibliográfica e foi realizada nas bases da Biblioteca Digital Brasileira de Teses e Dissertações (BDTD) e do Portal de Periódicos da Capes onde foram analisados trabalhos produzidos de 2010 a 2020.

A busca dos trabalhos foi realizada em Março de 2020, primeiramente na BDTD com opção de busca avançada, utilizando como descritores os termos "Propagação de calor", "Transferência de calor", "Transmissão de calor" com correspondência da busca para qualquer um dos termos, os campos usados foram assunto, título e resumo (um de cada vez) o que resultou em 167 trabalhos no total. Em seguida realizou-se uma nova busca no site de periódicos da Capes utilizando descritores 
correspondentes aos anteriores, resultou em 134 resultados no total. A análise dos trabalhos foi feita de maio a junho de 2020.

Na sequência das buscas foi feita a seleção dos trabalhos pela verificação de títulos e resumos, foram descartados os trabalhos cujo títulos continham palavras que demonstravam se tratar claramente de pesquisas não voltadas para o ensino, dos demais foi feita a análise dos resumos e restaram somente cinco trabalhos da BDTD e um dos periódicos da Capes que atendem aos interesses dessa pesquisa, portanto restaram seis trabalhos voltados para o Ensino Médio realizados no Brasil para dá seguimento ao estudo.

Após essa seleção do material foi dado continuação a pesquisa com uma análise mais detalhada e interpretação de dados dos 6 trabalhos que fizeram parte desse estudo. Foi analisado o panorama, ano e proveniência desses trabalhos, bem como tipo (artigo, dissertação ou tese). Buscou-se também interpretar o que foi realizado em cada um deles e de que forma, categorizando, métodos e estratégias de ensino utilizadas, fundamentação dos métodos e abrangência específicas dos conteúdos abordados.

Por fim organizou-se os resultados em quatro tópicos caracterizados por diferentes assuntos que respondem a problematização inicial da pesquisa.

\section{ANÁLISE DOS TRABALHOS}

\subsection{PANORAMA DA PRODUÇÃO ACADÊMICA}

Dos 301 trabalhos encontrados utilizando os descritores apresentados, foram selecionados apenas 6 após a filtragem dos trabalhos feita através da análise dos títulos e resumos, esses trabalhos foram publicados nos últimos 4 anos, conforme apresentado na tabela 1, com destaque para o ano de 2018 que foi o que teve mais trabalhos publicados no tema. 
Tabela 1- Número de trabalhos por ano.

\begin{tabular}{|l|l|}
\hline Ano & Número de trabalhos \\
\hline 2019 & 1 \\
\hline 2018 & 3 \\
\hline 2017 & 1 \\
\hline 2016 & 1 \\
\hline
\end{tabular}

Fonte: Dados da pesquisa-março (2020)

Embora a pesquisa compreenda um período de 10 anos, os trabalhos que foram encontrados estão distribuídos apenas entre os anos de 2016 a 2019 e sem crescimento continuo nessas publicações, durante a pesquisa percebeu-se um grande número de trabalhos que tratam desses processos, porém a maioria deles são experimentais e laboratoriais, o que aponta uma necessidade de continuidade de pesquisas na área de ensino. Dos seis, cinco são dissertações (BDTD) e somente um artigo científico (Periódicos Capes). Essas pesquisas são provenientes de quatro cursos de formação distintos, como exposto na Tabela 2:

Tabela 2- Proveniência dos Trabalhos

\begin{tabular}{|l|l|}
\hline Curso & $\begin{array}{l}\text { Número de } \\
\text { trabalhos }\end{array}$ \\
\hline $\begin{array}{l}\text { Mestrado Profissional em Ensino de Física (MPEF) } \\
\text { Mestrado profissional em Ensino de Ciências Exatas } \\
\text { (MPECM) }\end{array}$ & 1 \\
\hline $\begin{array}{l}\text { Mestrado Profissional em Ensino de Ciências e } \\
\text { Matemática (MPECM) }\end{array}$ & 1 \\
\hline Licenciatura em Física (LF) & 1 \\
\hline
\end{tabular}

Fonte: Dados da pesquisa-março (2020)

Nota-se então que a maioria desses trabalhos foram produzidos em cursos de nível mestrado profissional, por isso em sua maioria são dissertações, prevalecendo o 
Mestrado profissional em ensino de Física, e isso mostra a importância desses cursos profissionais, que no geral o docente tem que propor a solução de um problema com ênfase na sua área, e no caso do MPEF o docente propõe soluções de problemas no ensino de Física pertencente a sua própria realidade, isso contribui para desenvolvimento e melhoria do ensino visto que o mestrando desenvolve o estudo na sua própria realidade que pode coincidir com outras e logo servirá de apoio a outros docentes em outros locais.

Destes trabalhos, apenas um foi realizado em escola particular, os demais foram desenvolvidos em escolas da rede pública, variando entre escolas municipais e estaduais e um Instituto Federal.

Esses cursos são distribuídos em diferentes estados e instituições, os provenientes do MPEF foram desenvolvidos em Pernambuco- Universidade Federal de Pernambuco, Paraná- Universidade Estatual de Ponta Grossa e RoraimaUniversidade Federal de Roraíma; do MPECM na Paraíba- Universidade Estadual da Paraíba; MPEC em Rio Grande do Sul-; Universidade do Vale do Taquari e de LF no Acre-Universidade Federal do Acre abrangendo três regiões brasileiras, o que leva a acreditar ser um problema em nível nacional.

De acordo com Silva (2019) os resultados de pesquisas na área do ensino de Ciências da natureza, como a Física, revelam alternativas metodológicas que direcionam a melhoria do processo de ensino e aprendizagem, por exemplo, sequências didáticas, uso de tecnologias digitais, ensino investigativo, ensino por projetos; uso da história e epistemologia da ciência, metodologias ativas.

No Quadro 1 estão dispostos os trabalhos analisados nessa pesquisa:

Quadro 1 - Trabalhos sobre o ensino de processos de transferências de calor

\section{Trabalho Descrição}

T1

NOVACOSKI, Marilene Probst. O Arduino na programação de experiências em termodinâmica e em física moderna. 2016. $208 \mathrm{f}$. 
Dissertação (Mestrado Profissional em Ensino de Física) - Programa de Pós-graduação em Ensino de Física. Universidade Estatual de Ponta Grossa. 2016. Ponta Grossa-PR

T2

SILVA, Maurício Veiga da. Robótica educacional: um recurso para a exploração de conceitos relacionados à transferência de calor no ensino médio. 2017. Dissertação (Mestrado em Ensino de Ciências Exatas) Programa de Pós-Graduação em Ensino de Ciências Exatas; Universidade do Vale do Taquari. 2017. Lajeado -RS

T3 Barreto, Ivaldy José Nóbrega. Fogão solar do tipo caixa: Relato de uma experiência didática para o ensino de propagação do calor. 2018. $237 f$. Dissertação (Mestrado Profissional em Ensino de Ciências e Matemática) - Programa de Pós-graduação em Ensino de Ciências e Matemática. Universidade Estadual da Paraíba. 2018. Campina Grande.

T4 BARBOSA, Suliene Alves. Uso de dispositivos confeccionado com materiais de fácil acesso para auxiliar na aprendizagem do conceito de propagação de calor aplicado no ensino médio. 2019. 114f. Dissertação (Mestrado Profissional em Ensino de Física) - Programa de Pósgraduação em Ensino de Física. Universidade Federal de Roraíma. 2019. Boa Vista-RR.

T5 SILVA, José Cícero Dias da. Aprendizagem motivada através de aulas experimentais: uma proposta ao ensino de física utilizando a propagação do calor por condução em um fio de cobre linear.2018. 95f. Dissertação (Mestrado Nacional Profissional em Ensino de Física) -Programa de Pósgraduação em Ensino de Física. Universidade Federal de Pernambuco. 2018. Caruaru-PE.

T6 AMORIM, Aline Mariane Alves de; REIS, Joisilany Santos dos; OLIVEIRA, Victoria Cristina Morais; SANTOS, Bianca Martins. Jogo de mímica para o ensino de propagação do calor: condução, convecção e irradiação. Revista Prática Docente. v. 3, n. 1, p. 158-170, jan./jun. 2018.

Fonte: Dados da pesquisa- março (2020) 
A dissertação T1 usou a placa Arduino em experimentos de Termodinâmica, para medidas de temperatura ambiente, discussão sobre sensação térmica e processos de propagação de calor e também na abordagem de temas de física moderna, foi construído um cubo metálico, similar ao cubo de Leslie comercial e outro modificado, foram feitas medidas da temperatura em tempo real das faces do cubo, utilizando a placa integrada Arduino, sensores de temperatura NTC e sistema de aquisição dos dados (PLX DAQ). Além da produção dos cubos foi produzido um guia de introdução ao Arduino e um roteiro de experiências relacionadas à Termodinâmica e a Física Moderna.

O T2 aborda o uso de atividades de robótica como recurso tecnológico para a exploração de conceitos relacionados à transferência de calor no Ensino Médio, as atividades foram desenvolvidas no laboratório de robótica da própria escola, bem como a abordagem teórica dos conteúdos. Foi utilizado o kit de robótica LEGO MINDSTORMS® NXT e o software LEGO MINDSTORMS® NXT, ambos disponibilizados pela escola, foi realizada com alunos que têm disciplina de robótica.

O T3 utilizou experimento de baixo custo como ferramenta didática no ensino de propagação de calor por meio de um fogão solar do tipo caixa. A proposta foi dividida em 4 oficinas nas quais foram feitas montagem dos fogões, experimentação dos mesmos e coleta de dados por meio dos sensores térmicos acoplados ao fogão e analise da eficiência dos fogões a partir do estudo do conteúdo propagação do calor. A pesquisa utilizou os momentos pedagógicos de Delizoicov e a placa Arduino para medir o aquecimento real dos fogões.

No T4 Foram desenvolvidas aulas experimentais de Física com um dispositivo educacional de propagação de calor. Seguiu os processos da teoria da aprendizagem significativa, foi feita montagem do experimento pelos alunos e aplicação do dispositivo educacional nas aulas. Considerou conhecimentos prévios, e realização de aula teórica antes da experimentação foi montado um dispositivo para cada processo. 
O T5 trata de conceitos indispensáveis ao estudo de propagação do calor em corpos sólidos através de experimentos. Os autores trabalharam conceitos relacionados a propagação de calor por condução, realizando aulas experimentais e teóricas.

O T6 usou um experimento de baixo custo, resolução de exercícios, execução do jogo de mímica "Gesticulando a Física", foi realizado uma sequência didática no $3^{\circ}$ ano do Ensino Médio, por meio de projeto de extensão. A aula proposta incluiu a apresentação teórica dos conteúdos, especificamente sobre calor sensível, calor latente e os processos de transmissão de calor.

\subsection{ESTRATÉGIAS DE ENSINO UTILIZADAS}

Com base nas descrições apresentadas sobre a realização de cada uma das pesquisas classificou-se as publicações em três categorias diferentes de acordo com a forma que as mesmas foram desenvolvidas, essas categorias estão apresentadas na Tabela 3.

Tabela 3 - Categorias das pesquisas

\begin{tabular}{|l|l|}
\hline Categoria & Número de trabalhos \\
\hline Sequência didática & 4 \\
\hline Oficinas & 1 \\
\hline Projeto de extensão & 1 \\
\hline
\end{tabular}

Fonte: Dados da pesquisa - março (2020)

Percebe-se uma predileção pelo desenvolvimento de sequências didáticas (2/3 dos trabalhos produzidos). Duas dessas sequências didáticas foram realizadas durante as próprias aulas da disciplina de Física, as demais em contraturno das aulas regulares, assim como as oficinas e o projeto de extensão que foi realizado por bolsistas do Programa Institucional de Bolsas de Iniciação à Docência (PIBID).

As sequências didáticas prevalecem nessas pesquisas e é notável que elas permitem uma melhor estruturação e torna-se mais confiável avaliar a eficácia e contribuições 
da implementação das metodologias para o ensino através delas. No trabalho T6, Amorim et al. (2018) comentam que a utilização da sequência didática proposta estimulou aos alunos à compreensão e fixação do conteúdo de forma facilitada e divertida.

Para Nascimento (2010) é necessário refletir tanto para decidir o quanto ensinar a Física, como para ordenar tais assuntos e também a maneira de utilizar as atividades práticas e como proceder a uma avaliação justa e rigorosa do que foi aprendido. $\mathrm{O}$ autor complementa ainda que o ensino da Física tem que ser estruturado de uma forma que permita ao professor trabalhar melhor e ao estudante aprender melhor também.

Em todos os trabalhos foi possível perceber essa estruturação, e resultados positivos em relação ao conhecimento alcançado pelos discentes, isso reflete a importância de um bom planejamento, e de atividades estruturadas para a obtenção de bons resultados.

Quanto as estratégias de ensino utilizadas no desenvolvimento das atividades para o ensino dos processos de transferência de calor, os trabalhos foram categorizados conforme a tabela 4.

Tabela 4- Estratégias de ensino aplicadas

\begin{tabular}{|l|l|}
\hline Estratégias & Número de trabalhos \\
\hline Experimentos & 5 \\
\hline Aula teórica & 5 \\
\hline Jogo & 1 \\
\hline Slide & 1 \\
\hline Textos & 1 \\
\hline Mapa conceitual & 1 \\
\hline Atividade de Robótica & 1 \\
\hline
\end{tabular}

Fonte: Dados da pesquisa-março (2020) 
Foram utilizadas mais de uma das estratégias em cada trabalho, por isso o quantitativo ultrapassa o total de 6 , vale ressaltar que todas elas foram testadas e permitiram o alcance dos objetivos, portando contribuíram para aprendizagem.

A maioria dos trabalhos $(83,33 \%)$ apresentaram atividades experimentais como forma de facilitar, melhorar entendimento e despertar interesse nos estudantes, foram realizados experimentos com uso de laboratório, experimento tecnológicos e experimentos de baixo custo.

No trabalho T1 Novacoski (2016) relata que o uso da placa Arduino no ensino contribui para despertar o interesse através da aplicação prática de teorias e relações constituídas entre a vida cotidiana e o estudo da Física, influencia no reconhecimento da importância da Física bem como seu uso em diferentes tecnologias, assim as aulas experimentais são um estimulo para os estudantes e motiva a investigação científica.

Em T2 Silva (2017) explica que o uso de recursos tecnológicos, em especial os recursos inovadores, proporcionam aos estudantes uma maneira diferente de visualizar e abordar conceitos teóricos na prática, especialmente os conceitos sobre transferências de calor, pois muitas vezes os estudantes não conseguem reconhecer sua aplicabilidade e perceber a importâncias para o cotidiano ao estudarem a teoria.

Porém sabe-se que o uso de robótica e tecnologias mais avançadas, não é viável para a realidade da maioria das escolas brasileiras, é necessário que os discentes conheçam um pouco sobre robótica para uso desse tipo de metodologia e além disso precisam de recursos para essa implementação nas escolas.

Na dissertação T3 Barreto (2018, p.13) ressalta que "o ensino de processos de propagação do calor não é tarefa fácil, pois ensinar propagação de calor envolve aspectos importantes e presentes no dia a dia". O autor acrescenta sobre o uso de experimentos de baixo custo que os mesmos podem ser compreendidos como uma alternativa, na falta de laboratórios e viabilizam a execução de atividades similares as de laboratório, ajuda na prática pedagógica para o ensino de Física e facilita a compreensão dos conteúdos. 
Mesmo utilizando de outras estratégias os autores fizeram uso também das aulas teóricas, alguns utilizaram somente depois dos experimentos. Na dissertação T5 Silva (2018) defende que ao realizar aulas experimentais e em seguidas aulas teóricas, os estudantes demonstram mais interesse nos conceitos, porque novas ideias e interpretações são provocadas durante o experimento, e isso melhora o aprendizado, que se torna mais significativo, e consequentemente provoca melhor resultado nas avaliações. Em T4 Barbosa (2019) explica que o experimento demonstra uma situação real, reproduzida pelo mediador para explicar fenômenos naturais, e é uma atividade que tem intuito de desenvolver aprendizagem significativa.

Em T6 Amorim et al (2018) comenta que utilizar recursos diferentes dos tradicionais nas aulas de Física facilita o processo de ensino aprendizagem, e é importante usar recursos didáticos nos quais os estudantes participem ativamente, como: jogos, cinema, teatro e tirinhas, aulas experimentais, entre outros.

Esses trabalhos mostram formas diversificadas de tornar o ensino mais atrativo que podem auxiliar o trabalho docente. Os experimentos não são apenas instrumentos facilitadores para os discentes, e não devem ser usados apenas como algo "extraordinário" que provoque admiração neles, é um método de ensino que amplia as possibilidades de o docente trabalhar o conteúdo e deve ser bem planejado.

As outras práticas que foram utilizadas nessas pesquisas também são muito importantes para aprendizagem jogos, mapas conceituais, slides, aulas teóricas, textos que trazem, muitas vezes, informações mais atualizadas do que os matérias didáticos também são importantes.

O uso de metodologias ativas e atualizadas, não é uma opção para reprimir as tradicionais, pelo contrário é uma complementação. Percebeu-se que as aulas teóricas prevaleceram antes das atividades experimentais, mas em dois trabalhos ela veio somente depois. Mesmo inovando os métodos tradicionais permanecem, pois eles são necessários é preciso diversificar os métodos, não abandonar os tradicionais, e sim utilizá-los juntamente com novos. T5 Silva $(2018$, p. 13) "para que haja um 
aprendizado verdadeiramente significativo é importante um enlaçamento entre aulas teóricas e experimentais".

No T1 Novacoski (2016) explica que usar diferentes tecnologias, manipular objetos, utilizar produtos de baixo custo, pesquisar para aprender um determinado conteúdo, são possibilidades de atrair e ensinar os estudantes, na busca de maneira de facilitar, uma vez que facilitar não significa tornar fácil retirando conteúdo do currículo, por exemplo, mas facilitar tem que estar ligado a maneira de ministrar os assuntos. Dessa forma:

Os alunos quase nunca têm oportunidade de vivenciar alguma situação de investigação, o que lhes impossibilita aprender como se processa a construção do conhecimento físico. A utilização de atividades experimentais bem planejadas facilita muito a compreensão da produção do conhecimento em física, e sem compreensão, é difícil aprender a disciplina. (NASCIMENTO, 2010, p. 18).

Machado (2015) comenta que metodologias ativas, que se respaldam no papel participativo do estudante, onde o professor é um mediador que direciona a busca de informações e produção de conhecimentos, são viáveis para aprendizagem de forma ativa permitindo vivenciar situações que o incitam a refletir e gerar conhecimento.

Vitor e Silva (2017) entendem que trabalhar, durante as aulas, textos científicos que não estão no livro didático, mas que tenham relação com os conteúdos é importante para aprofundar o entendimento científico e enfatizar um contexto ao estudo.

\subsection{FUNDAMENTAÇÃO DOS MÉTODOS DE ENSINO}

As teorias de ensino nas quais os trabalhos fazem referência e que fundamentaram os métodos de ensino apresentados nos mesmos estão dispostas na tabela 5 a seguir:

Tabela 5- Teorias que fundamentaram os métodos de ensino das pesquisas

\begin{tabular}{|l|l|}
\hline Teoria & Número de trabalhos \\
\hline Aprendizagem significativa & 3 \\
\hline Momentos pedagógico de Delizoicov & 1 \\
\hline
\end{tabular}




\begin{tabular}{|l|l|}
\hline Linha Construtivista & 1 \\
\hline Não informada & 1 \\
\hline
\end{tabular}

Fonte: Dados da pesquisa-março (2020)

Metade dos trabalhos referenciaram a aprendizagem significativa de Ausubel, e desenvolveram suas atividades iniciando com a investigação dos conhecimentos prévios, buscando a valorização desses conhecimentos. Barbosa (2019) comenta, sobre aprendizagem significativa que a mesma consiste basicamente em relacionar uma nova informação com outra preexistente que serve como âncora para dá significado ao estudo e aprendizagem de novos conhecimentos, que contribuem para os que eles já tem. "Ressalta-se, portanto que a aprendizagem significativa exige do estudante uma postura proativa, ou seja, que este se interesse pela aprendizagem da temática determinada" (HABERMANN e COELHO, 2019, p. 15).

Um dos trabalhos utilizou os Momentos Pedagógico de Delizoicov na metodologia de ensino, Barreto (2018) diz que os momentos pedagógicos de Delizoicov são problematização inicial, organização do conhecimento e aplicação do conhecimento na busca de tornar a prática eficaz, e que estes podem mudar de ordem para adequação da atividade.

A Linha construtivista inspirada nas ideias de Piaget também foi usada em um trabalho, Silva (2018) relatou que usar meios para aproximar o conteúdo abordado do estudante e evidenciar que tal conteúdo está presente nas atividades humanas e naturais, proporciona uma aproximação com a realidade, e assim o estudante compreende o assunto de maneira construtivista, ele mesmo constrói o conceito ao invés de recebê-lo pronto.

Quase todas as pesquisas foram fundamentadas e referenciaram teorias de ensino, com exceção de um dos trabalhos, isso revela a importância dos docentes (incluindo os das áreas de exatas) conhecerem teorias de ensino, para que possam aplica-las nas aulas, e desenvolver novos métodos que aprimorem a prática docente e melhore 
o processo ensino/aprendizagem, possibilitando aos estudantes o desenvolvimento das habilidades que a sociedade atual exigi.

\subsection{ABORDAGEM ESPECÍFICA DO CONTEÚDO}

Em cada trabalho foram abordados, além dos três processos de transmissão de calor condução, convecção e radiação, outros conceitos e conhecimentos relacionados ao tema os quais estão dispostos na Tabela 6.

Tabela 6- Conteúdos abordados nos trabalhos

\begin{tabular}{|l|l|}
\hline Conteúdo & $\begin{array}{l}\text { Número } \\
\text { trabalhos }\end{array}$ \\
\hline $\begin{array}{l}\text { Abordagem conceitual dos três processos de } \\
\text { transmissão }\end{array}$ & 6 \\
\hline Aplicações & 6 \\
\hline Conceitos de calor, temperatura e sensação térmica & 4 \\
\hline Escalas Termométricas & 3 \\
\hline Lei de Fourier & 3 \\
\hline Física Moderna/Lei de Stefan & 1 \\
\hline Calor sensível e Latente & 1 \\
\hline Primeira Lei da Termodinâmica & 1 \\
\hline Meio Ambiente & 1 \\
\hline
\end{tabular}

Fonte: Dados da pesquisa-março (2020)

Todos as produções analisadas trabalharam esses processos apresentando aplicações e consequentemente fazendo relação com uso cotidiano desses conhecimentos, como resolução de situações problemas e interpretação do mundo, o que vai de acordo com as competências específicas de ciências da natureza e suas tecnologias para o Ensino Médio, Brasil (2017 p. 544) apresenta como uma das competências: 
Analisar situações-problema e avaliar aplicações do conhecimento científico e tecnológico e suas implicações no mundo, utilizando procedimentos e linguagens próprios das Ciências da Natureza, para propor soluções que considerem demandas locais, regionais e/ou globais, e comunicar suas descobertas e conclusões a públicos variados, em diversos contextos e por meio de diferentes mídias e tecnologias digitais de informação e (TDIC).

Em todos os trabalhos incluídos nessa pesquisa é feita referência a importância de relacionar esse conteúdo com o cotidiano, com situações práticas reais, pela proximidade que este tem com situações reais e também pela importância desse conhecimento para tomada de atitudes rotineiras do dia a dia. Entre as principais situações cotidianas exemplificadas através dos processos de transmissão de calor abordadas nesses trabalhos tem-se:

- Uso inadequado dos conceitos calor e temperatura no dia a dia.

- Sensação térmica (quente e frio).

- Posição dos aparelhos resfriadores de ar.

- A interferência da cor dos objetos na taxa de absorção de energia.

- Aquecimento do celular quando é usado por muito tempo.

- Diferença de temperatura em diferentes pontos do mesmo ambiente.

- Utilização de matérias de acordo com a taxa de condutividade

- Efeito estufa

- Inversão térmica

Quatro trabalhos exploraram os conceitos de calor, temperatura e sensação térmica que são bastante utilizados diariamente, porém normalmente são confundidos. No T2 faz-se referência a confusão de alguns termos usados no cotidiano, o autor esclarece que "no estudo da transferência de calor é importante a definição de alguns conceitos como calor e temperatura, que geralmente, são confundidos por muitas pessoas" (SILVA, 2017, p.30).

Apenas em três trabalhos foi abordada a lei de Fourier, embora a mesma esteja aplicada ao estudo do processo de condução. Foi possível notar que a inserção de novas metodologias, não impediu a exploração de cálculos pertinentes ao estudo, 
embora esse conteúdo seja mais conceitual, pôde-se notar que houve aplicações de cálculos em medidas de temperatura, comparações, escalas termométricas e em situações problemas.

Em T5 Silva (2018, p. 17) explana que:

A termodinâmica é de grande importância no estudo das ciências, embora seja uma área de origens práticas, conectadas com os avanços da primeira revolução industrial, e de enorme potencial de contextualização, evidenciada em fenômenos cotidianos, sua modelagem matemática pode se tornar complexa e abstrata.

Foram abordados também, com menor frequência, Física Moderna/Lei de Stefan, Calor sensível e Latente, Primeira Lei da Termodinâmica e Meio Ambiente. As abordagens desses trabalhos trazem a visão de que existem formas necessárias e eficazes de trabalhar os processos de transmissão de calor, que desenvolvem conhecimentos essenciais para o dia a dia, estruturam o ensino de uma maneira facilitadora e desenvolvem habilidades que não são divergentes das habilidades atualmente exigidas pela sociedade e pelos documentos direcionadores da educação.

\section{CONSIDERAÇÕES FINAIS}

Percebe-se, pelos os dados obtidos nessa pesquisa, que os trabalhos sobre processos de transmissão de calor publicados na última década no Brasil voltados para o ensino no nível médio são poucos.

É notável em quase todos o uso de experimentos e a referência a aplicações cotidianas, ver se também através dos relatos a relevância de considerar os conhecimentos prévios, principalmente porque esse é um conteúdo que traz conceitos que os estudantes utilizam bastante, e normalmente de forma equivocada, essa valorização do que eles já conhecem irá ajudar a interpretar melhor as novas informações, bem como ajudará a atraí-los para a aula.

Nos trabalhos a contextualização é feita através de exemplificações de aplicações cotidianas do conteúdo, demonstrações com experimentos e de ferramentas 
tecnológicas, e ao final de todos eles os autores apresentaram resultados positivos quanto a aprendizagem dos estudantes e também no envolvimento e motivação para o estudo.

No entanto compreende-se que a produção cientifica na área de ensino das ciências exatas precisa ter continuidade, pois são de grande importância para melhoria do ensino, são necessárias mais pesquisas quem apoiem o trabalho docente diante das tantas exigências do mundo atual.

Com esses resultados é notório que ao se falar de atividades diversificadas e melhorias no ensino de Física, os experimentos são os primeiros a serem dispostos isso se deve a possibilidade de demonstrar na prática os conteúdos, porém a possibilidade de diversificar as aulas não pode depender exclusivamente da viabilidade de realizar experimentos ou de outros materiais disponíveis, há outras atividades que também podem ser interessantes, e mesmo quando se falar de experimento não precisa está diretamente ligado a um laboratório.

Ensinar para desenvolver habilidades de uso cotidiano, não se trata de facilitar os conteúdos, ou de excluir os cálculos matemáticos que são essenciais para o aprendizado de Física, mas trata-se de adequar e conduzir o estudo não só com foco exclusivo na matemática, e nem somente no contexto prático, e sim em ambos.

Reconhece-se também a importância do conhecimento das teorias de ensino para o desenvolvimento da prática docente, tal conhecimento está diretamente relacionado a formação inicial e continuada de professores.

\section{REFERÊNCIAS}

AMORIM, Aline Mariane; ALVES, Reis, Josilany Santos; OLIVEIRA, Victoria Cristina Morais, \& SANTOS, Bianca Martins. (2018). Jogo de mímica para o ensino de propagação do calor: condução, convecção e irradiação. Revista Prática Docente. 3(1), 158-170. https://doi.org/10.23926/RPD.2526-2149.2018.v3.n1.p158-170.id142. 
ARAUJO, Ione dos Santos Canabarro; CHESINI, Talita Sganderla; FILHO, João Bernardes Rocha. (2014). Alfabetização Científica Concepções de Educadores. Contexto \& Educação, 29(94), 4-26.

BARBOSA, Suliene Alves. (2019). Uso de dispositivos confeccionado com materiais de fácil acesso para auxiliar na aprendizagem do conceito de propagação de calor aplicado no ensino médio. (Dissertação Mestrado Profissional em Ensino de Física) - Programa de Pós-graduação em Ensino de Física da Universidade Federal de Roraíma. Boa Vista-RR.

BARRETO FILHO, Benigno, \& SILVA, Carlos Xavier. Física aula por aula: Mecânica dos Fluídos, termologia e óptica, 3ㄹeㄹ. São Paulo: FTD, 2016, 290p, v2.

BARRETO, Ivaldy José Nobrega. (2018). Fogão solar do tipo caixa: Relato de uma experiência didática para o ensino de propagação do calor. (Dissertação Mestrado Profissional em Ensino de Ciências e Matemática) - Programa de Pós-graduação em Ensino de Ciências e Matemática da Universidade Estadual da Paraíba. Campina Grande.

BRASIL. Base Nacional Comum Curricular: Ensino Médio. Brasília: MEC/Secretaria de Educação Básica, 2017.

GONÇALVES FILHO, Aurélio; TOSCANO, Carlos. Física: Interação e tecnologia, $1^{\underline{a}}$ ed. São Paulo: Leya. 2013, 232p, v2.

HABERMANN, Diovana Santos \& COELHO, Franciele Braz de Oliveira. (2019). Estudo de conceitos do princípio de Arquimedes com uso de ambiente virtual de aprendizagem. In: M. S. Passoni (Org). Pesquisa em Ensino de Física. (pp. 12-28) Ponta Grossa: Atena Editora. Disponével em: https://www.atenaeditora.com.br/wpcontent/uploads/2019/03/E-book-Pesquisa-em-Ensino-de-F\%C3\%ADsica.pdf.

MACHADO, Marta de Azevedo. (2015). O ensino de física térmica na perspectiva da aprendizagem significativa: uma aplicação no ensino médio. (Dissertação 
Mestrado Nacional Profissional em Ensino de Física) - Programa de Pós-Graduação em Ensino de Física da Universidade Federal de Ouro Preto. Ouro Preto.

MARTINI, Gloria; SPINELLI, Walter; REIS, Hugo Carneiro; SANT ANNA, Blaidi. Conexões com a Física, 3ํㅡ ed. São Paulo: Moderna, 2016, 287p, v2.

NASCIMENTO, Tiago Lessa. (2010). Repensando o ensino da física no ensino médio. (Monografia Licenciatura Plena em Física) - Universidade Estadual do Ceará, Centro de Ciências e Tecnologia. Fortaleza.

NOVACOSKI, Marilene Probst. (2016). O Arduino na programação de experiências em termodinâmica e em física moderna. (Dissertação Mestrado Profissional em Ensino de Física) - Programa de Pós-graduação em Ensino de Física da Universidade Estatual de Ponta Grossa. Ponta Grossa-PR.

PEREIRA, Marta Maximo. (2020). Sentidos do (e no) Ensino de Física no Ensino Médio: articulações com a teoria histórico-cultural. Caderno brasileiro de Ensino de Física, 37(1), 1-5. https://doi.org/10.5007/2175-7941.2020v37n1p1

SANT' ANNA, Blaidi; MARTINI, Gloria; REIS, Hugo Carneiro \& SPINELLI, Walter. Conexões com a Física 2, $1^{\text {a }}$ ed. São Paulo: Moderna, 2010, 447p, v2.

SILVA, José Cícero Dias. (2018). Aprendizagem motivada através de aulas experimentais: uma proposta ao ensino de física utilizando a propagação do calor por condução em um fio de cobre linear. (Dissertação Mestrado Nacional Profissional em Ensino de Física) -Programa de Pós-graduação em Ensino de Física da Universidade Federal de Pernambuco. Caruaru-PE.

SILVA, Maria Géssica. (2019). As leis da Termodinâmica com abordagem da Modelagem Científica de Mario Bunge e uma sequência de Ciclos de Modelagens de David Hestenes desenvolvida em uma turma do ensino médio na cidade de Acopiara. (Dissertação Mestrado Nacional Profissional em Ensino de Física)- Programa de Pós-Graduação em Ensino de Física da Universidade Regional do Cariri. Juazeiro do Norte. 
SILVA, Maurício Veiga. (2017). Robótica educacional: um recurso para a exploração de conceitos relacionados à transferência de calor no ensino médio. (Dissertação Mestrado em Ensino de Ciências Exatas) - Programa de Pós-Graduação em Ensino de Ciências Exatas da Universidade do Vale do Taquari. Lajeado -RS.

VITOR, Fernanda Cavalcanti; SILVA, Ana Paula Bispo. (2017). Alfabetização e educação científicas: consensos e controvérsias. Rev. bras. de Estudos pedagógicos, 98(249), 410-427. https://doi.org/10.24109/21766681.rbep.98i249.2637.

Enviado: Novembro, 2020.

Aprovado: Janeiro, 2021. 